\title{
Fake news in the time of environmental disaster: Preparing framework for COVID-19
}

\author{
Syeda Saadia Azim ${ }^{1}$, Dipayan Dey ${ }^{2}$, Amitava Aich ${ }^{2}$ and Arindam Roy ${ }^{2 *}$ \\ ${ }^{1}$ U.S. Consulate -Kolkata, India \\ ${ }^{2}$ South Asian Forum for Environment, Kolkata, India
}

\begin{abstract}
The increasing trend of environmental disaster due to changing climate has escalated the occurrence of Tsunami, Forest fire, Flood, Epidemics and other extreme health and environmental and hazardous events across the globe. Establishment of effective and transparent communication during the crisis phase is extremely important to reduce the after-effects of the events. In recent times, fake news or news with fabricated content have emerged as major threats of communications during and and post -disaster phase. The present study critically evaluates the nature and consequences of fake news spread during the four major environmental disasters in recent era (Fukushima Nuclear Disaster, Keralan Flood, Amazon Forest Fire and African Ebola Epidemic) and prepared a framework for present COVID-19 Pandemic. The criticality and potential threat created by the fake news have been quantified and analyzed through the timeline of news spreading. It has been observed that the adverse impact related to the African Ebola Epidemic was highest due to its multiple fake news origin sites, both online and offline propagation methods, well fabricated content and relatively low effort on containment. However the COVID-19 pandemic is an ongoing disaster expected to have a long- drawn impact covering most countries in the world with combined consequences hence it tends to overtake all other events. Policy recommendations have been prepared to combat the spreading of fake news during the present and future environmental disasters. The importance of the study relies on the fact that the number of environmental disasters will increase in future and strategy for risk communication during the time is still not explored adequately. In addition the study will contribute significantly for understanding the present status of information paradigm for COVID-19 and helps in preparing region-specific real-time contingency measures for effective risk communication.
\end{abstract}

Keywords: Fake News, Disaster and Crisis Management, Extreme Events, Risk Communications, health and environmental hazards, COVID-19

arindam.safe@gmail.com 


\section{Introduction}

Disruption of societal functionality or disaster is a consequence of natural or technological hazards associated with resource loss, environmental degradation, economic damage and health impact and societal disruptions (Burnham, 2008; Haddow, 2008; Bradley et al. 2016) . An increasing trend of disaster is observed since the last decades due to the recent change in global land use, population outburst and climate change (Huppert and Sparks, 2006; Lowrey et al., 2007; Mayhorn and McLaughlin). The recent IPCC report clearly suggests an increased intensity of extreme events as a form of drought, floods, forest fire, tsunami and tornados in next several decades across the globe (IPCC Report 2014). As per multiple recently conducted studies, change in climate also has also elevated the subsequent increment of viral, bacterial and protozoan epidemics in different parts of the world (Williams et al., 2016; Pauli et al., 2017) and pandemics such as COVID-19 as the world is witnessing now. Prevention, preparedness, response and recovery are the four crucial stages of disaster and proper communication during the crisis that helps to reduce the impact of the disaster (Bradley et al., 2016). Risk communication is defined as the process or methods of effectively communicating with people during the time of exceptional stress or emergency (US EPA, 2018). Previously, risk communication, especially during disaster, was a one-way channel of information; from government to the public (Reynolds and Seeger, 2012). However, due to technological advancement in modern telecommunication, currently interactive mode of risk communication has been established due to social media, online commentary in news feed and messenger (Glik, 2007) and several other virtual platforms. Harvard Kennedy School on Media, Politics and Public Policy has quoted "The Internet has reduced many constraints on dissemination of news. This allows outlets that do not embody these norms to compete online with those that do on a relatively more equal footing than was possible offline. This has contributed to the abandonment of traditional news sources that had long enjoyed high levels of public trust and credibility." (The Science of Fake news, Shorenstein Center, 2018).

The risk communication from government to public has often been found to be inadequate due to "People might panic", "People do not need to know" and "Speculation might increase the unrest" as suggested by Sandman (2011) and Fischhoff (2011). According to the experts, responsible circulation of information including the speculative risk and worst case scenario might be absolutely crucial to avoid misconception among the community (Figueroa, 2013). Fake news has been identified as a major threat at global perspective and has been able to influence the presidential election (Shao et al., 2017), disease outbreak (Brainard and Hunter, 2019), hate crime (Schäfer and Schadauer, 2018) and racism (Shimizu, 2020). At the time of social media and the internet, the effect of fabricated lies propagated through mimicking news content for achieving multiple benefits have increased exponentially. Counteracting the emerging trend requires empowering individuals to detect fake news in the internet and algorithm-based prevention of fake news spreading by using robust statistical methods and artificial intelligence 
(Garnik and Mesyura, 2017; Lazer et al. 2018). The number of literature connecting the effect of fake news on disaster is remarkably low. In the present study, we handpicked four environmental disasters to fill the gap of knowledge on how fake news propagates during different environmental disasters occurring over different atmospheric environments affecting different ethnological populations around the globe and then translate the understanding into the present emerging epidemic outburst.

As the SARS-CoV-2 virus - more popularly known as COVID-19 - has spread around the globe, conspiracy theories and rumour mongering have also gone viral on social media platforms and other outlets. World Health Organization Director-General Tedros Adhanom Ghebreyesus rightly said in February, "We're not just fighting an epidemic; we're fighting an infodemic". On March 27, 2020, the World Health Organization held a media briefing to update the public about the COVID-19 outbreak. And they made pertinent points cautioning the public on the veracity of the information they were accessing. They said "Reacting to raw numbers can be "very, very unhelpful" and not ensure you understand your country's response effort. Blaming countries with rising numbers can lead to disincentives to report and test. With no proven treatment, don't allow misinformation to create drug shortages that can be used to treat other diseases". The objectives of the present study are a) To critically analyze the propagation of fake news during past and present notable environmental and health disasters, b) To evaluate the impact and mitigation strategy taken by Government c) To establish a policy framework for combating fake news during present COVID-19 outbreak and future environmental disaster.

\section{Methodology}

\subsection{Brief description of selected environmental disaster}

Fukushima Nuclear power plant was hit by an earthquake followed by a Tsunami on Mar 11, 2011, which led to significant radiation leakage which is considered as the most severe nuclear disaster after Chernobyl. One and half lakh residents were evacuated immediately and multiple people were hospitalized due to radiation burns, injuries and one was officially died due to cancer from the accident. Total financial loss is accounted for \$188billions. During mid August of 2018, heavy monsoonal rainfall followed by dam discharges and landslides have caused millions of people to evacuate and $\$ 400$ of property damage. With 480 people dead and 143 people missing, one sixth of the population of Kerala directly affected by the flood. Beginning in Jan 2019, Amazonian forest fire caused the burning of $9060 \mathrm{sq} \mathrm{km}$ of forest. More than 40000 fire counts were estimated from satellite data and this leads to extensive damage in wildlife and biodiversity. The fire is majorly driven by slash and burn agriculture and prolonged drought period due to global warming. With a total 11323 world-wide deaths, African Ebola outbreak is considered as one of the most massive epidemics in recent history. Guinea, Liberia,Mali, Nigeria 
and Sierra Leone were the worst affected countries. 28616 cases were registered with $40 \%$ of fatality rate. In 2018, a second phase outbreak was reported in Congo and Uganda with total confirmed cases of 3305 and total death count of 2268. As regard to COVID1-9 the impact is an ongoing assessment of social and economic health of people, countries, communities and their cultures. The corona virus spanning 199 countries has killed more than one lakh fifty thousand people (as of April 18, 2020) globally until now and the numbers are counting. It is very difficult at this point to evaluate the larger impact of the pandemic and that caused by the want of risk communication.

\subsection{Review and search methods}

The paper has analyzed the previous literature of fake news and environmental disaster through a series of web portal searches, independent social media analysis and book reviews. Appropriate keywords have been selected and search was undertaken in Google, Google Scholar, Web of Science, Pubmed and multiple digital fake news databases (LibGuide, Politico, The Harvard Kennedy School Misinformation Review, Global Media Manipulation Case Book (GMMCB)). Newspaper articles, blogs, online news portal, scientific literature, thesis and commentary for each disaster have been selected for further analysis. The assessments are being done to quantify the impact of fake news, malinformation and misinformation regarding COVID -19 till mid of April, 2020.

\section{Results and discussion}

\subsection{General characterization of Fake News}

The overall list of fake news propagated as a function of time for four environmental and health disasters has been given in Fig 1 .

\subsubsection{Fukushima Nuclear Disaster}

Right after the disaster, an overall propaganda stating the failure of nuclear energy was circulated through social as well as conventional print and audio-visual medium. Two significant misinformations were spread globally years after the Fukushima incident. i) A radioactive pollution map depicting Tsunami wave height over Pacific ocean was falsely attributed as radioactive level in the ocean water (Jacob, 2018). The rumor mostly spread through online news media portal and was detected as fake content after months. ii) Dramatic rise of thyroid cancer and leukemia after the nuclear disaster (Sawano et al. 2019). Sadly it was initially circulated by local city council members through leaflets followed by massive propagation in social media (Owen, 2019). Months after its circulation in national and international media, a commentary in a reputed scientific journal proved the content as false and doctored. Another unfair and biased news was the increase of radiation exposure at an unimaginable level. It was falsely propagated 
on online news mediums along with news of surveillance robots melt-down due to the high radioactivity level (Middleton, 2017). However, these news items were classified as fake and debunked at the earliest convenience. Two other news of mutated flowers in the radiation zone and Alaskan fish getting cancer for the Fukushima disaster went viral in social media and both conspiracy theories were found to be fake within days of the circulation (Evon, 2015; Funke, 2019)

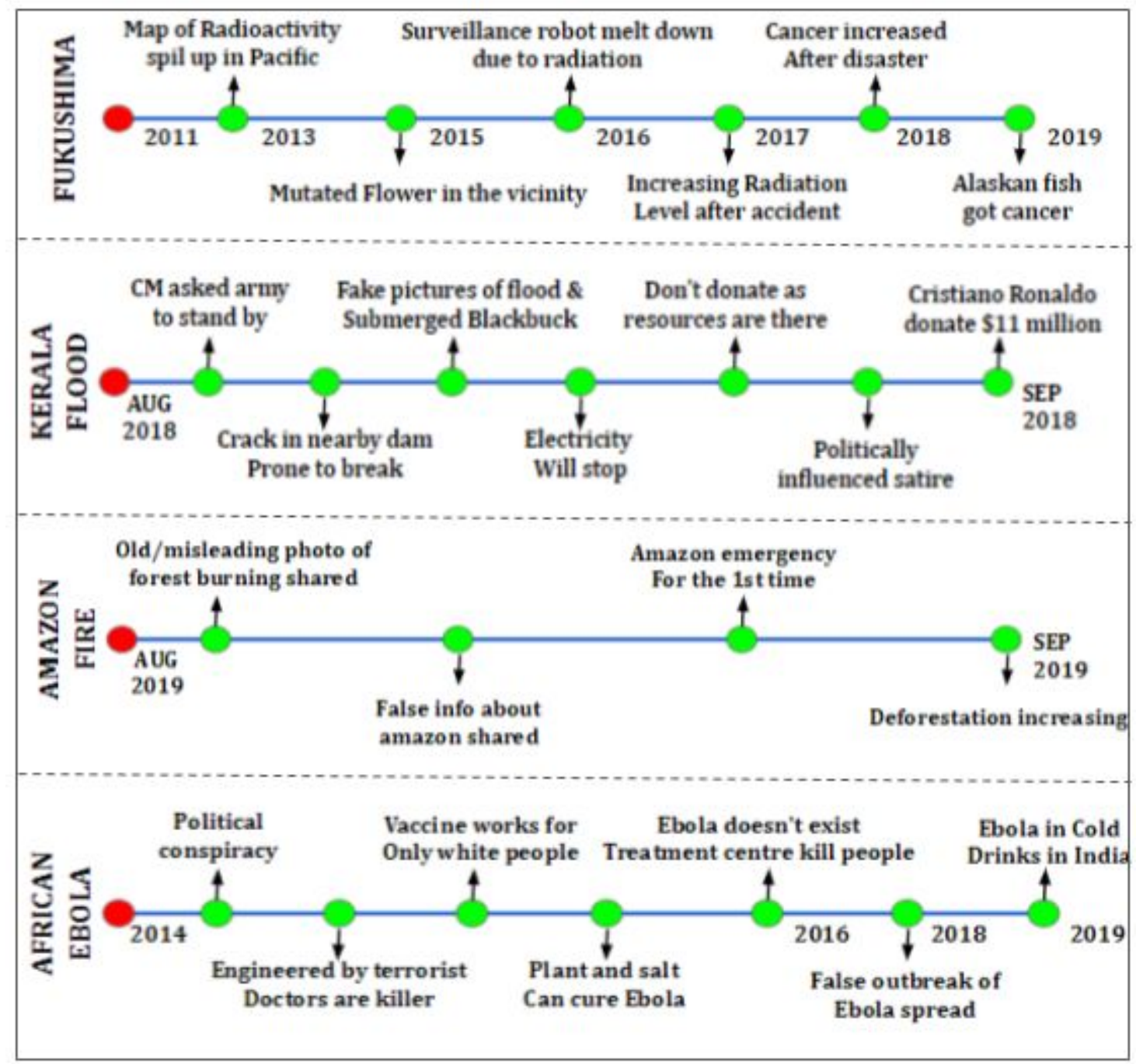

Fig 1: Fake news along with the time-line for four selected disasters

\subsubsection{Kerala Floods}

The Kerala floods also brought the flood of misinformation in social media and online news portal within a very short interval (Saroop and Augustine, 2019). An audio message was circulated rapidly through whatsapp stating that cracks were detected in Mullaperiyar Dam and it would burst and kill millions of Keralites (Pravin, 2019). An UK-based news agency also made the mistake of reporting the same without verification. Government officials had to issue 
an office order to prevent the spreading of the rumours. Another propaganda news went viral on twitter articulating that Kerala CM stopped Army involvement for rescuing flood victims (Verbrugge, 2018). A tweet from Indian Army finally debunked the disinformation within hours of the fake news propagation. Entirely fabricated news of entire state electric shut down and discriminatory partisan audio clips of Keralite being too rich to receive relief help during flood emergency circulated on Whatsapp circuits (Sneha, 2018). Satire news as men do not want to wear a saffron life jacket due to political differences spread on online news portals along with the pictures of past flood affected zones and sweeping out of animals in flood water (Kundu, 2018). False news of an eleven million dollar donation by Chritiano Ronaldo has also circulated within a few days of the Kerala flood (LiveMint, 2018).

\subsubsection{Amazonian Forest Fire}

The fire episodes over Amazon rainforest had started a series of misinformation spread in the internet. Old photographs of forest fire (Not even Amazonian forest), distressed animals, firefighters and saved souls were shared by thousands of people including celebrities like Madonna, Christiano Ronaldo, Leonado de Caprio, Novak djocovik and French Prime Minister Emmanuel Macron (Shellenberger, 2019). Millions of followers of these celebrities also start sharing these mis-informations on social media sites. Along with pictures, misinformation such as "Amazon is the lungs of the planets" or "It produces $20 \%$ of the earth's oxygen", was widely spread through Twitter, Instagram, Facebook and Whatsapp. A narrative based propaganda was created where Amazonian fires were portrayed as the first of its kind and exceptionally devastating in nature. The data was fabricated and it took almost a month to label the whole narrative as fake news and it was found that Amazon forest fires were very common and higher frequency was observed compared to 2019 in previous years such as 2016, 2012 and 2010 (Wirtz, 2019). Fake news like the highest rate of deforestation during the forest fires had spread in the news whereas the truth revealed a lower deforestation rate compared to last decade (Nepstad, 2019). However, it took a good amount of time before the well furnished partisan mal-information was detected as fake.

\subsubsection{African Ebola Epidemic}

The fake news that was spread in the time of African Ebola epidemic were multi-layered, spontaneous, emotional fabrication of dis-information, mis-information and mal-information. A part of it was entirely political, where rumors like Ebola being an engineered disease was spread extensively through Whatsapp (Martin, 2019). Racially influenced news like anti-Ebola medicines were fake tablets that killed people and the vaccine worked for white people only spread through social media and word-of-mouth instantaneously (Martin, 2019). "Ebola patients have risen from death" and "Ebola is an act of terrorism" were also being propagated very fast through social media and personal communications (Martin, 2019; Spinney, 2020). Denial and 
disbelief spread so much that the treatment centre for Ebola was termed as a death house by the locals. Mal-information about cures and medicines was also circulated within weeks using twitter and whatsapp. For example, Ewedu plants or blood transfusion or drinking salt water could cure ebola (Oyeyemi, 2014). It was also found that there was an intentional effort to spread a rumor that there was nothing called Ebola (as believed by one in every four citizen in Congo, the country worst hit by the disease) and that it was a political disease (Vinck et al. 2019). This caused massive unrest in the society and treatment centres were being attacked around Congo (Sweeney, 2019). Long after the Ebola event, false outbreak news was spread in Ghana, USA and other parts of the globe (Ghana Health Service, 2018; Wilson, 2019). Major TV channels and news portals sometimes unintentionally helped to spread that kind of mis-information. Another misinformation spread in Hyderabad, India, stated the occurrence of Ebola virus in Softdrinks, spread rapidly through social media (TOI, 2019).

\subsection{Classification and threat potential of fake news}

Through credible news sources "Fake news is defined as the information deliberately fabricated and published with the intention to deceive and mislead others into believing falsehoods or doubting verifiable facts". The fake news have been classified as mis-information, dis-information and mal-information according to Wardle and Derakhshan (2017). In brief, mis-informations are honest mistakes which do not intend to harm whereas dis-informations are fabricated narratives created with the intention to harm or influence others. Mal-informations are right information in the wrong context to initiate hatred against a particular person, community or organization or piece of information. The percentage contribution of mis-information, dis-information and mal-information for all four environmental and health disaster types have been represented in Fig 2. The contribution of mis-information among the total fake content circulated for four environmental disasters is: Forest Fire (Amazon) $>$ Flood $($ Kerala) $>$ Nuclear (Fukushima) $>$ Epidemic (Ebola).

Higher proportion of mis-information during amazon forest fire indicates most of the fake news were hoax with minor or no adverse consequences. However, a minimal proportion of mis-information (less than 10\%) was observed in the Ebola epidemic spread out which indicates the majority of the fake news was created to intentionally harm a particular group or community. Higher fraction of mal-information during Epidemic (Ebola) events clearly suggested that the spreading of fake information was not at all an act of spontaneous passion but it was a deliberate attempt to mislead people for political or monetary gain. More than $70 \%$ of the fake news circulated during the Fukushima disaster and Kerala floods were either fabricated or placed deliberately. The ratio of total information (sum of mis-information, dis-information and mal-information) to mis-information can be used as an indicator of damaging potential and the ratio is found to be highest in case of Ebola Epidemic (12) followed by Fukushima nuclear 
disaster (3.5), Kerala Floods (3) and Amazonian forest fire (2). Therefore in this study, the Ebola epidemic was found to be the most impactful in terms of adverse effects.

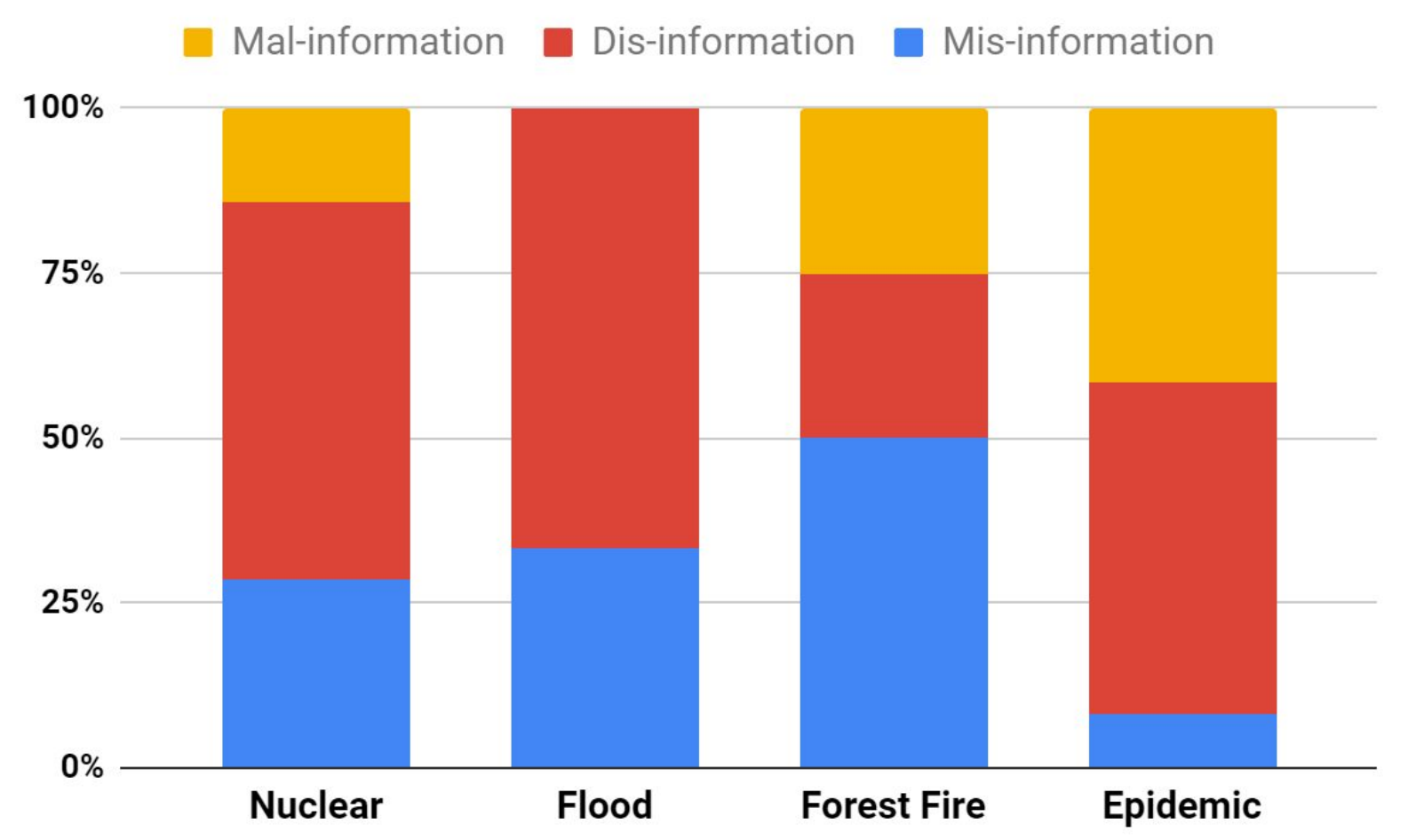

Fig 2: Types of fake informations in four environmental disasters

\subsection{Fake News and Detection: Timeline and Mitigation}

The time point of origin and the time for detection of different types of fake news have been represented in Table 1 for four environmental and health disasters. It can be observed that the mis-informations usually originate earlier than dis-information and mal-information. For all four types of disaster, the detection of mis-information is also very rapid (within hours/days of origin). In most of the cases, active and concerned social media users help to detect the mis-information. In some cases, mis-information was detected by online news portals and established media organizations. However, due to the well fabricated nature of dis-information and mal-information, the detection usually took higher time (days and months) compared to mis-information detection. Due to the long-lasting effect of nuclear disaster, the fake news originated even 7-8 years after the incident. Observations from Kerala Floods indicated the containment of all types of fake news were done within hours/days of origin. Due to the huge spatial area, multiple affected sites and extended timeline, fake news related to African Ebola epidemic also originated on a longer time scale. The most diverse sources of fake news origin 
were observed in African Ebola Epidemic where messenger platforms, social media, print media, television media and word of mouth; all were involved at some point of time.

Table 1: Origin and detection periods for fake informations

\begin{tabular}{|c|c|c|c|}
\hline Disaster Name & Information Types & $\begin{array}{l}\text { Origin time point } \\
\text { (After the disaster) }\end{array}$ & $\begin{array}{l}\text { Fake detection } \\
\text { (After spreading) }\end{array}$ \\
\hline \multirow{2}{*}{$\begin{array}{c}\text { Fukushima } \\
\text { nuclear disaster }\end{array}$} & Mis-information & Months/Years & Days \\
\hline & Dis/Mal information & Months/Years & Months \\
\hline \multirow[t]{2}{*}{ Kerala Flood } & Mis-information & Hours/Days & Hours/Days \\
\hline & Dis/Mal information & Days & Days/Weeks \\
\hline \multirow{2}{*}{$\begin{array}{c}\text { Amazon Forest } \\
\text { Fire }\end{array}$} & Mis-information & Hours/Days & Days \\
\hline & Dis/Mal information & Days/Weeks & Months \\
\hline \multirow[t]{2}{*}{ Ebola in Africa } & Mis-information & Months/Years & Days \\
\hline & Dis/Mal information & Months/Years & Months \\
\hline
\end{tabular}

Due to the diversity of information and its dissemination, a diverse set of audience controlling or studying the impact of an infodemic is a very challenging matter.. In the above four cases community based door-to-door campaign, official notice, performance by local artists, campaign in radio and television was launched during the time-period. However, it was not very effective as during later stages an increasing number of supporters of conspiracy theory were observed in social media. Fake news associated with Kerala Flood and Amazon Forest Fire mostly spread through Whatsapp and Twitter. Government officials, IT cell and police department worked together by starting an anti-campaign in social media, releasing government orders, police reporting against the fake campaigner and arresting them to stop spreading fake news at earliest convenience. Social media and news portals were associated with fake news circulation after the Fukushima nuclear disaster and the containment involved government notifications and media coverage falsifying the hoax.

\subsection{Fake news during COVID-19}

In case of COVID -19 it was found to be a concoction of mis, dis and mal -information making the scenario fit for fake news. The spreading of the virus through Bat and Pangolin is one of the popular misinformation that was shared in social media leading to the creation of the big fake news kit bags. "Corona Virus was infecting only Chinese people because they ate wild animals" 
and "Chinese people stopped eating non-vegetarian food" are the kind of mis-information which propagate instantaneously in social media. Dis-information and mal-information are spreading rapidly through internet e.g. the origin of the virus from failed biological experiments; the virus is a result of genetic modification; Covid-19 can be cured by ingesting fish-tank cleaning products containing chloroquine; self-medication of Hydroxychloroquine, medicine used to treat malaria, can prevent the virus; homeopathy medicine and ingestion of bovine excreta can protect from Coronavirus. Misinformation of several celebrities (Cristiano Ronaldo and Pope) tested as Corona positive spread during early hours. Fake news on Nostradamus prophecies about Coronavirus in 2020 and conspiracy theories published in books/movies are becoming widespread instantaneously. Trade war between U.S. and China; shifting of responsibility towards a particular religion and sending corona-affected terrorists to neighbouring countries are recent examples of mal-information outspread.

Since little information came out of the highly secretive Chinese government in the initial days of the virus spread, the dis-information and mal-information scenario preceded the mis -information scene. And as the epidemic turned to pandemic, and the amount of fear it generated because of less information, a concoction of mis, dis and mal information along with a mix of facts kept pouring, leading to an infodemic. The World Health Organization worries that in fighting the Covid-19 pandemic in the present scenario, they must also combat an infodemic, which it defines as "an overabundance of information - some accurate and some not - that makes it hard for people to find trustworthy sources and reliable guidance when they need it." P.W. Singer and Emerson T. Brooking in their prescient book Like War:The Weaponization of Social Media, (October 2018) write that the United States is engaged on a new battlefield defined by the "speed, spread, and accessibility of information."

\section{Discussion}

The fake news related to the Fukushima disaster does not spread very quickly. The very well doctored mal-information started spreading years after the incident and created a global impact escalating fear and disbelief against nuclear power. $70 \%$ of the fake news was classified as "False attribution", "Misinformation" and "Bogus" which had a serious long-lasting impact on society, economics and health. Due to the well fabricated nature, the containment of the fake news took months. In case of Kerala Floods, with minor exception, most of the fake news was propagated through social media like Twitter, Whatsapp and Facebook (Varghese and Yadukrishnan, 2019). The propagation began within days of the events and the detection as fake was completed within hours-to-days time frame. Partisan, error, misinformation and satire are the major forms of fake news detected. $50 \%$ of the fake news could be classified as high impact as they were motivated by politics and power. However the other $50 \%$ could be interpreted as neutral or low impact form of fake news with minor or no further consequences. The containment of the fake news was done at a remarkably fast pace due to the fast response from 
the government and civic society which in turn reduced the impact. 32 complaints were lodged and 5 people were arrested for spreading mis-information (Mathrubhumi, 2018). The majority of the fake news in Amazon forest fire was classified as harmless misinformations that had no direct impact. The rest of fake news were mostly politically influenced either making governments or Amazonians or Soybean cultivation as responsible for the fire events. Although debatable and suffering from lack of evidence, lots of information was intentionally fabricated or created during the course of time to establish the conspiracy theories. Sadly, climate change did not figure even in the first page during the fire episodes. The escalating number of drought periods and its correlations with forest fires had remained as a little discussed topic in mainstream and social media. All fake news started within days and the detection got delayed due to well fabrication. The highly alarming factor in the fake news spreading during African Ebola epidemic was the proliferation of mis-information via word of mouth which made it much difficult to contain. The complexity increased due to the political and racial nature of the fake news (Scrase, 2020). The Red Cross and WHO working in the African continent faced resistance in the form of verbal abuse, refusal to take medicine and even violence. Clinics were destroyed and a senior epidemiologist was killed by the protester. The Red Cross tried to gather information to draw a rumor map and deployed community volunteers to build resistance against the false rumors. Supernatural theories also arose that related corona with witchcrafts and demons. The fake news could be classified as "Misinformation", "Conspiracy theory", "Partisan", "Pseudo-science" and "Propaganda". All of them had major impacts in the economy, society and mankind.

In the case of COVId-19, it is still an ongoing assessment process. The evaluation process will be long drawn due to continued fake and unverified, unscientific claims. But given the impact of the issue, the Government of India, Ministry of Information and Technology passed an advisory for users of social media platforms, stating that there was a trend of circulation of misinformation/false news and sharing of anonymous data in various social media platforms creating panic among the public". (letter dated 20.03.2020, no: 16(1)/2020-CLES) Social media platforms must inform their users not to host, display, upload, modify, publish, transmit, update or share any information that may affect public order and unlawful in any way. In the case CoVID19, most governments had to issue advisories and initiate action for criminal offences seeing the massive scale of fake information regarding the disease that endangered lives. Chinese measures to contain the virus in Hubei Province. (Chinese unprecedented strict measures of complete lockdown in the Wuhan area, stop dissemination of information, controlled information flow, social media posts of students from Wuhan and the readying of hospitals added more suspicion than confidence across the globe.

\section{Policy Recommendations}

1. Transparent clarification and sensible dissemination of information from government websites/social media pages is extremely important to contain the spread of the fake news. 
Technical terminology needs to be converted into mass language for better understanding. Proliferation of the information will be done through sensible users in the social medium. 2. The socio-economic status of the affected region is extremely important as literacy level and racial/religious/political conflict in the region might elevate the threats from the fake news spreading. Extra precautionary measures need to be taken for sensitive areas. 3. Fake news associated with disaster with long lasting health effects like nuclear or toxin spillage can be propagated years after the incident. Therefore, long-term combat plans with proper monitoring of data and its reporting is extremely needed. 4. Off-line or word of mouth rumour/hoax can be more damaging compared to an online counterpart. To prevent off-line fake news community intervention, door-to-door meetings and usage of conventional communication tools (radio, road theater) is necessary. 5. Identification of dis-information and mal-information is necessary as these two are the major harmful components of fake news. Mis-information has little or no effect in the longer run. 6. Well understanding of Government-Media-Public nexus in the affected region is useful to design strategy for preventing generation as well as circulation of fake news.

\section{Real-time Contingency planning for COVID-19: World's first social media pandemic}

It has been found that two important strategies stem the flow and influence of fake news; empowering people to better evaluate the credibility of news and news sources they encounter; and bringing structural changes aimed at preventing exposure to fake news in the first place. The observation during Kerala Flood indicates intervention by the Government and enforcement of disciplinary action are extremely important for rapid containment of fake news. It was also observed that the racial and religious sensitivity and inclinations can instigate resistance (African Ebola); mis-interpretation of scientific data can stimulate propaganda by different lobbies (Amazon Forest Fire); and mal-informations can be spread years after the disaster took place (Japan Nuclear Disaster).

COVID-19 is the first ever social media pandemic where the population is relying on social media feeds more than ever. Though researchers are on the job to ascertain factors to handle the infodemic, it is now a tested and trial method that seems to work. The world economic forum recommended three factors to address the infodemic at this point.

1) Relying on evidence based science information: A good science journalist will always refrain from making comments such as "scientific evidence process that"...so be skeptical about those claims and embrace uncertainty-responsibly because science itself is process and sometimes different studies present evidences that can be contradictory (which is fine)

2) To be mindful of where the information is coming from. If there is breakthrough discovery then it will definitely be highlighted in all creditable platforms. Alone whatsapp messages with a certain claim with no evidence to back it should be thought about deeper. 
3) Who is backing up the claim? During the present scenario of COVID-19 pandemic there's been a lot of information with claims such as "I'm not a virologist or epidemiologist but..." "or this is a preventive medicine and not curative", so ideally people should be wary of scientists in unrelated disciplines.

The present study proposes five crucial contingency plans for the current scenario which needs to be executed rapidly. a) Formation of Govt. portal for divulgence of essential informations through online and offline/door-to-door methods; b) Preparation of a task-force by the netizen volunteers for identification and reporting of fake news in social media; c) Presence of multiple COVID-19 information apps/websites are creating a massive state of confusion and this can be avoided by formation of central nationwide transparent open sourcing informations dissemination system; d) The results from the scientific studies regarding COVID-19 are often misinterpreted and therefore the any scientific study published during the present time of crisis should consist an executive summary section of mass reader and policy maker; e) Information gaps/ lack of data should be addressed and a two-way mode of communication with the government and the people needs to be established through citizen forum.

\section{References}

- Ghana Health Service. (2018). Fake News of Ebola In Ghana. https://www.ghanahealthservice. org/ghs-item-details.php?scid=22\&iid=142

- Wilson, R. (2019). Ebola outbreak in Africa spreads fake news in America. The Hill. Jun 12. https://thehill.com/policy/international/448197-ebola-outbreak-in-africa-spreads-fake-ne ws-in-america

- Spinney L (2020) Why Vaccines Do Not Work Without Trust. Frontier For Young Minds. 7:160. doi: 10.3389/frym.2019.00160

- Martin, A. (2019). Ebola is killing people but rumours about Ebola are killing even more. Independent. Jun 15. https://www.independent.co.uk/independentminds/long-reads/fake-news-ebola-outbreakdrc-red-cross-a $8956816 . h t m l$

- Sweeney, A. (2019). Community Mistrust: why the DRC's Ebola epidemic is so distinctly complex. EISF. Jul 9. https://www.eisf.eu/news/community-mistrust-why-the-drcs-ebola-epidemic/

- Scrase, A (2020). EBOLA AND FAKE NEWS IN THE DEMOCRATIC REPUBLIC OF THE CONGO. Thesis. Aalborg University, Denmark. https://projekter.aau.dk/projekter/files/306261282/THESISFINALSCRASE52.pdf

- Oyeyemi, S. O., Gabarron, E., \& Wynn, R. (2014). Ebola, Twitter, and misinformation: a dangerous combination?. Bmj, 349, g6178.

- TOI. (2019). FACT CHECK: Did Hyderabad Police claim soft drinks contain Ebola virus? Times of India. Jun 4. 
https://timesofindia.indiatimes.com/times-fact-check/news/fact-check-did-hyderabad-poli ce-claim-soft-drinks-contain-ebola-virus/articleshow/69650217.cms

- Vinck, P., Pham, P. N., Bindu, K. K., Bedford, J., \& Nilles, E. J. (2019). Institutional trust and misinformation in the response to the 2018-19 Ebola outbreak in North Kivu, DR Congo: a population-based survey. The Lancet Infectious Diseases, 19(5), 529-536.

- Tsubokura, M., Onoue, Y., Torii, H. A., Suda, S., Mori, K., Nishikawa, Y., ... \& Uno, K. (2018). Twitter use in scientific communication revealed by visualization of information spreading by influencers within half a year after the Fukushima Daiichi nuclear power plant accident. PloS one, 13(9).

- Nakayama, C., Sato, O., Sugita, M., Nakayama, T., Kuroda, Y., Orui, M., ... \& Rudd, R. E. (2019). Lingering health-related anxiety about radiation among Fukushima residents as correlated with media information following the accident at Fukushima Daiichi Nuclear Power Plant. PloS one, 14(5).

- Sawano, T., Ozaki, A., Hori, A., \& Tsubokura, M. (2019). Combating 'fake news' and social stigma after the Fukushima Daiichi Nuclear Power Plant incident- the importance of accurate longitudinal clinical data. QJM: An International Journal of Medicine, 112(7), 479-481.

- Jacob, F. (2018). Take hope: This Fukushima disaster map is a fake. Big Think, Oct 18. (https://bigthink.com/strange-maps/fake-map-fukushima-disaster-radiation)

- Middleton, J. (2017). Fake News: Fukushima Edition. WUWT, Feb 17. (https://wattsupwiththat.com/2017/02/17/fake-news-fukushima-edition/)

- Evon, D. (2015). Are Mutated Daisies Growing Near Fukushima? Snopes. July 22. (https://www.snopes.com/fact-check/nuclear-mutant-daisies/)

- Fanke, D. (2019). A viral post claims fish in Alaska are getting cancer because of $\begin{array}{lllll}\text { Fukushima. They } & \text { aren't. } & \text { Politifact. } & \text { Sep }\end{array}$ (https://www.politifact.com/factchecks/2019/sep/11/facebook-posts/viral-post-claims-fish -alaska-are-getting-cancer-b/)

- Owen, L. H. (2019) Nuclear disasters, information vacuums: How a lack of data in Fukushima led to the spread of fake health news. NiemanLab. Jul 12. (https://www.niemanlab.org/2019/07/nuclear-disasters-information-vacuums-how-a-lackof-data-in-fukushima-led-to-the-spread-of-fake-health-news/)

- Pravin, R. S. (2019). In Kerala, fake news floods social media, adds to panic. The Hindu. Aug 10.

https://www.thehindu.com/news/national/kerala/in-kerala-fake-news-floods-social-media -adds-to-panic/article28965647.ece

- Sneha, A. (2018). Kerala Floods: Fake News About 'Dam Burst', 'No Power' Create Panic. BoomLive. Aug17.

https://www.boomlive.in/kerala-floods-fake-news-about-dam-burst-no-power-create-pani c) 
- Kundu, C. (2018). Fact Check: Now fake news floods Kerala. IndiaToday. Aug 20. https://www.indiatoday.in/fact-check/story/kerala-floods-fake-news-fact-check-1319187$\underline{2018-08-20}$

- LiveMint (2018). Fake news adds to Kerala flood torment. Aug 12. https://www.livemint.com/Politics/KLgnO07lu36dnKi2GXk78M/Fake-news-adds-to-Ker ala-flood-torment.html

- Verbrugge, L. (2018). Fighting Fake News in Kerala. WPMU. Oct 9. http://wpmu.mah.se/nmict182group2/2018/10/09/fighting-fake-news/

- Mathrubhumi. (2018). Fake campaign on social media against flood relief activities: 32 cases registered, 5 arrested. Aug 14.

- https://english.mathrubhumi.com/news/kerala/fake-campaign-on-social-media-against-flo od-relief-activities-32-cases-registered-5-arrested-1.4041628

- Varghese, R. R. and Yadukrishnan T A, (2019), "Role of social media during Kerala floods 2018". Library Philosophy and Practice (e-journal). 2754. https://digitalcommons.unl.edu/libphilprac/2754

- Saroop, KP., \& Augustine, R. (2019). FAKE NEWS IN SOCIAL MEDIA: AN ANALYTICAL STUDY ON KERALA FLOOD. International Journal of Science Research and Review. Vol 7 (5).

- Wirtz, B. (2019). Data on Amazon Rainforest Fires Tell a Much Different Story Than Social Media. Foundation for Economic Education. Sep 5. https://fee.org/articles/data-on-amazon-rainforest-fires-tell-a-much-different-story-than-s ocial-medial

- Nepstad, B. (2019) The myths and the truth about the fires in the Amazon CNN. Sep 5. https://edition.cnn.com/2019/09/05/opinions/amazon-fires-myths-and-truth-opinion-nepst ad/index.html

- Shellenberger, M. (2019). Why Everything They Say About The Amazon, Including That It's The 'Lungs Of The World,' Is Wrong, Forbes. Aug 26. https://www.forbes.com/sites/michaelshellenberger/2019/08/26/why-everything-they-say -about-the-amazon-including-that-its-the-lungs-of-the-world-is-wrong/\#3d0013d25bde

- Wardle, C., \& Derakhshan, H. (2017). Information disorder: Toward an interdisciplinary framework for research and policy making. Council of Europe report, 27.

- Granik, M., \& Mesyura, V. (2017, May). Fake news detection using naive Bayes classifier. In 2017 IEEE First Ukraine Conference on Electrical and Computer Engineering (UKRCON) (pp. 900-903). IEEE.

- Shimizu, K. (2020). 2019-nCoV, fake news, and racism. The Lancet, 395(10225), 685-686. 
- Schäfer, C., \& Schadauer, A. (2018). Online fake news, hateful posts against refugees, and a surge in Xenophobia and hate crimes in Austria. Refugee News, Refugee Politics: Journalism, Public Opinion and Policymaking in Europe, 109-116.

- Shao, C., Ciampaglia, G. L., Varol, O., Flammini, A., \& Menczer, F. (2017). The spread of fake news by social bots. arXiv preprint arXiv:1707.07592, 96, 104.

- Brainard, J., \& Hunter, P. R. (2019). Misinformation making a disease outbreak worse: outcomes compared for influenza, monkeypox, and norovirus. Simulation, 0037549719885021.

- Lazer, D. M., Baum, M. A., Benkler, Y., Berinsky, A. J., Greenhill, K. M., Menczer, F., ... \& Schudson, M. (2018). The science of fake news. Science, 359(6380), 1094-1096.

- Paull, S. H., Horton, D. E., Ashfaq, M., Rastogi, D., Kramer, L. D., Diffenbaugh, N. S., \& Kilpatrick, A. M. (2017). Drought and immunity determine the intensity of West Nile virus epidemics and climate change impacts. Proceedings of the Royal Society B: Biological Sciences, 284(1848), 20162078.

- Williams, C. R., Mincham, G., Faddy, H., Viennet, E., Ritchie, S. A., \& Harley, D. (2016). Projections of increased and decreased dengue incidence under climate change. Epidemiology \& Infection, 144(14), 3091-3100.

- US- EPA. (2018) https://www.epa.gov/risk/risk-communication

- Burnham GM. Chapter 1: Disaster Definitions. In: Burnham GM \& Rand EC, editor(s). The Johns Hopkins and Red Cross and Red Crescent Public health guide in emergencies. Second edition. Geneva: International Federation of Red Cross and Red Crescent Societies, 2008.

- Haddow KS, Haddow G. Disaster communications in a changing media world. Butterworth-Heinemann, 2008

- Bradley, D. T., McFarland, M., \& Clarke, M. (2016). The effectiveness of disaster risk communication: a systematic review of intervention studies. In Effective Communication During Disasters (pp. 81-120). Apple Academic Press.

- Reynolds BS, Seeger MW. Crisis and Emergency Risk Communication. Atlanta. 2012

- Glik DC. Risk communication for public health emergencies. Annu Rev Public Health. 2007;28:33-54. PubMed PMID:17222081. [PubMed]

- Mayhorn, C. B., \& McLaughlin, A. C. (2014). Warning the world of extreme events: A global perspective on risk communication for natural and technological disaster. Safety science, 61, 43-50.

- Lowrey, W., Evans, W., Gower, K.K., Robinson, J.A., Ginter, P.M., McCormick, L.C., Abdolrasulnia, M., 2007. Effective media communication of disasters: pressing problems and recommendations. BMC Public Health 97 (7), 1-8.

- Huppert, H.E., Sparks, R.S.J., 2006. Extreme natural hazards: population growth, globalization, and environmental change. Philosophical Transactions of the Royal Society, Series A 364, 1875-1888. 
- Figueroa, P. M. (2013). Risk communication surrounding the Fukushima nuclear disaster: an anthropological approach. Asia Europe Journal, 11(1), 53-64.

- Fischhoff B (2011) The emotions of nuclear experts. Retrieved February 20, 2012, from http://www.thebulletin.org/ web-edition/features/the-emotions-of-nuclear-experts

- Sandman P (2011) Interview on The Futurist. Retrieved February, 20, 2012 from http://www.wfs.org/content/futurist-interviews-crisis-communications-expert-peter-sand man-fukushima-daiichi-nuclear-mel 